Goldschmidt 2021 Abstract

https://doi.org/10.7185/gold2021.7766

\section{Characterization of Nitrogen Isotopes in Oceanic Basalts}

\section{JOHN A KRANTZ, DAVID V BEKAERT, JOSHUA CURTICE AND PETER H BARRY}

Woods Hole Oceanographic Institution

Presenting Author: jakrantzphd@gmail.com

The large concentration contrast between nitrogen $(\mathrm{N})$ in Earth's atmosphere (78\%) and mantle materials (ppm) makes it a sensitive tracer of interactions between these reservoirs. To understand the origin and evolution of $\mathrm{N}$ in the mantle, we investigate two families of oceanic basalts: mid-ocean ridge basalts (MORB) and high ${ }^{3} \mathrm{He} /{ }^{4} \mathrm{He}$ plume-influenced basalts. The high ${ }^{3} \mathrm{He}$ signal in plume-influenced basalts is thought to be derived from an undegassed primordial component in the plume's mantle source [1].

We determine $\delta^{15} \mathrm{~N}$ for MORB samples from the Central Indian Ridge (CIR), Alarcon Rise, and Mid-Atlantic Ridge (MAR), as well as plume-influenced samples from Iceland, Lau, and Manus. Iceland and CIR data are in excellent agreement with previous studies [2,3]. In addition, we present 45 new $\mathrm{N}$ isotope measurements, nearly doubling the published global data set for oceanic basalts (Fig. 1). Average MORB $\delta^{15} \mathrm{~N}$ values range from -1 to $-5 \%$ (relative to air $=0 \%$ ), with each locality representing a distinct portion $\quad(\mathrm{CIR}=-1 \pm 1 \%$; $\quad$ Alarcon $=-2.3 \pm 1.3 \%$; $\mathrm{MAR}=-4.3 \pm 1.2 \%$ ). Plume-influenced samples, in contrast, have distinctly positive $\delta^{15} \mathrm{~N}$ values: Manus $=+0.3 \pm 0.9 \%$; Iceland $=+1.4 \pm 0.9 \%$; and $\mathrm{Lau}=+1.6 \pm 0.8 \%$.

The source of variation between MORB sample localities remains enigmatic but may be related to the proximity of plumeinfluenced basalts (CIR) and subduction zones (Alarcon). Iceland and Lau, on the other hand, are nearly identical. Notably, they are also marked by extremely high ${ }^{3} \mathrm{He} /{ }^{4} \mathrm{He}$ values $\left(>20 \mathrm{R}_{\mathrm{A}}\right)$ $[1,4,5]$. The correlation of high ${ }^{3} \mathrm{He} /{ }^{4} \mathrm{He}$ values with positive $\delta^{15} \mathrm{~N}$ suggests that positive $\mathrm{N}$ isotope anomalies are also derived from the primordial deep mantle (Fig. 2). Such anomalies could either be: 1) introduced by subduction of sediments with $\delta^{15} \mathrm{~N}=+5 \%$ \% $[3,7,8]$, or 2) a remnant of $\mathrm{N}$ isotope fractionation during core formation $[8,9]$.

Fig. 1: $\mathrm{N}$ isotope results of crushing experiments for MORB and high ${ }^{3} \mathrm{He} /{ }^{4} \mathrm{He}$ plume-influenced basalt. samples. Analytical uncertainty is $0.7 \%$, error bars are one-sigma.

Fig. 2: $\mathrm{N}$ isotope data vs. published ${ }^{3} \mathrm{He} /{ }^{4} \mathrm{He}$.

[1] Jackson et al., 2017. [2] Halldórsson et al., 2016. [3] Barry and Hilton, 2016. [4] Parai et al., 2019. [5] Hilton et al., 1993. [6] Barry and Broadley, 2021. [7] Marty and Dauphas, 2003. [8] Dauphas and Marty, 1999. [9] Dalou et al., 2019.
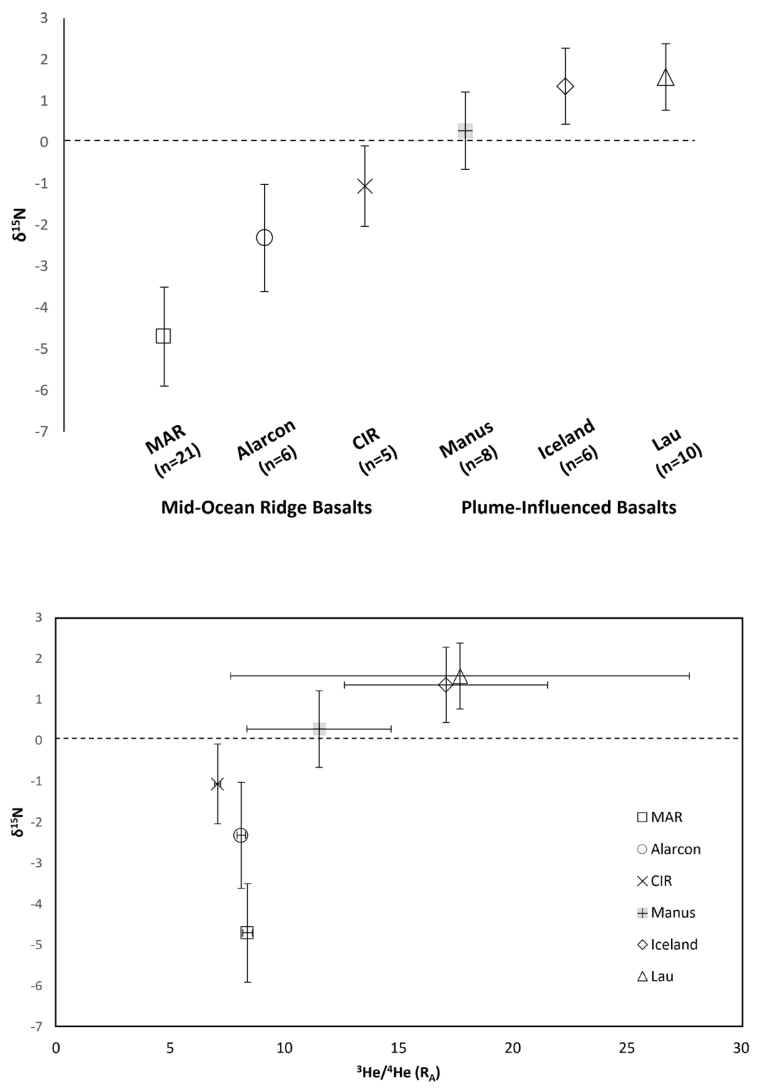